Factors affecting adoption in Wales:

\title{
Predictors of variation in time between entry to care and adoptive placement
}

Rebecca Anthony, ${ }^{1}$ Sarah Meakings, ${ }^{1}$ Julie Doughty, ${ }^{2}$ Heather Ottaway, ${ }^{3}$ Sally Holland ${ }^{4}$ and Katherine H. Shelton. ${ }^{1^{*}}$

1. School of Psychology, Cardiff University.

2. School of Law and Politics, Cardiff University.

3. School for Policy Studies, University of Bristol.

4. Children's Commissioner for Wales, formerly Cardiff University.

*Corresponding author. Email: Sheltonkh1@cardiff.ac.uk 


\section{Factors affecting adoption in Wales:}

\section{Predictors of variation in time between entry to care and adoptive placement}

\section{Highlights}

1. Children unable to live with birth family need timely plans for permanence.

2. This comprehensive study examined factors affecting adoption in Wales, UK.

3. The case files of 374 children placed for adoption were reviewed.

4. Several child characteristics were associated with longer time to placement.

\section{Introduction}

\section{Adoption and permanence}

Within the context of legislation, policy and practice in both England and Wales, there has been an increasing emphasis in recent years on reducing the delay in making permanent placements for children who cannot remain living with their birth parents (Department for Education (DfE), 2012, National Adoption Service, 2015). All children in local authority care for more than four months should have a plan for permanence. The framework for permanence centres on the maintenance of quality relationships between children and their carers (Boddy, 2013), to help provide children with 'a sense of security, continuity, commitment and identity' (DfE 2015: 22). In practical terms, this means ensuring that children 'have a secure, stable and loving family to support them through childhood and beyond' (DfE 2015: 22). Adoption is one of a range of permanence options for children unable to live safely with birth parents. Others include family and friends care and long- term fostering.

\section{$\underline{\text { Adoption and developmental outcomes }}$}


Most children adopted from the UK care system will have experienced abuse and/or neglect within their birth family (Selwyn, Meakings and Wijedasa, 2015). As a result of their early adverse life experiences (including for some, harm suffered in utero) and the potential for trauma, grief and loss through being removed from birth family and/or other primary carers, many children adopted today have a range of physical, emotional and social needs. Timely permanent placements are therefore emphasised in order to provide a stable and secure base through which children can recover developmentally (van den Dries, Juffer, van IJzendoorn, \& BakermansKranenburg, 2009) and thrive in the long-term (Palacios and Brodzinsky, 2010). Adopted children fare better than their peers who remain in care, with marked improvements in a range of developmental domains, including growth, security, attachment, behaviour and cognitive capabilities (van IJzendoorn and Juffer, 2006; Lloyd and Barth, 2011).

\section{Stability and disruption}

Placement stability is a component of permanence. It is an important measure to consider because stability and, in particular, early stability, has been linked to more positive developmental outcomes (Zima, Bussing, Freeman, Yang \& Forness, 2000; Harden, 2004; Rubin, O'Reilly, Luan \& Localio, 2007; Biehal, Ellison, Baker and Sinclair, 2010). Inevitably, some arrangements, intended as permanent, disrupt. The adoption disruption rates post-order in England and Wales have been calculated as being very low; 3.2\% in England over a 12 year period and 2.6\% over an 11 year period in Wales. They compare favourably with the disruption rates of special guardianship orders and residence orders (now called child arrangements orders), which over a five year period in England have disruption rates of 5.7\% and 14.7\% respectively (Selwyn, Meakings and Wijedasa, 2015). 
Previous research has indicated that a child's age at the time of their adoptive placement has a strong association with outcomes, insofar as the older the child when placed, the greater the likelihood of the adoption disrupting (Barth and Berry, 1988; Ivaldi, 2000; Dance and Rushton, 2005; Wijedasa and Selwyn, 2014). Moreover, an association has been found between children who wait in care longer to be placed with their adoptive families and later placement disruption (Selwyn et al., 2006; Selwyn, Meakings and Wijedasa, 2015). These factors, all linked to timeliness, demonstrate the importance of understanding those factors that predict delay. 


\section{Reasons for delay}

Adoption is arguably the most drastic of all family interventions, as it severs a child's legal ties to their birth family permanently. The decision to pursue adoption therefore has to be considered very carefully, and is one of the most complex and difficult aspects of a social worker's role. On the one hand, there is clear evidence about the consequences of delay for children. On the other hand, it has been argued that new legal timescales introduced in England and Wales do not allow enough time for birth families to evidence sustained change in their parenting in order to resume the care of their children (Gupta and Lloyd-Jones, 2014).

A comprehensive review of the family justice system in England and Wales (Family Justice Review 2011) highlighted delays in public law children's cases and made a series of recommendations, which included a statutory time limit of 26 weeks on court proceedings for care cases. This was introduced with effect from April 2014 and was intended to reduce the length of time taken by courts to reach decisions about placement plans. An overview of research evidence on child development and the impact of maltreatment was commissioned in response to the Family Justice Review, to assist decision-making by family justice professionals and facilitate a greater understanding of individual children's needs and appropriate timeframes (Brown and Ward, 2013). The English Government published an 'Action Plan on Adoption: tackling delay' (DfE, 2012), with a focus on tackling the causes and consequences of delay in relation to children being adopted. In Wales, the National Adoption Service (NAS) was established in 2014, following a National Assembly for Wales' Inquiry into Adoption that raised concerns about a number of issues, including delay (National Assembly for Wales, 2012). The National Adoption Service has set out, as a priority, their intention to place more children without delay (NAS, 2015). In England, in the year ending March 
2015 , the average time between a child entering care and moving in with their adoptive family was 18 months (Adoption Leadership Board, 2015). In Wales, the average time was 16.5 months (NAS, 2015). These time frames represent a large part of a (usually) young child's life.

\section{Child characteristics and the timeliness of adoption}

A range of child characteristics have been identified as affecting the timeliness of adoption. Age has been established as a strong predictor of adoption; the older the child, the less likely their plan for adoption will be realised (Connell, Katz, Saunders, and Tebes, 2006; Selwyn, Sturgess, Quinton and Baxter, 2006). Most prospective adopters express a clear preference for parenting younger children (Burge, Burke, Melklejohn and Groll, 2015; Selwyn, Meakings and Wijedasa, 2015).

Ethnicity also impacts on the timeliness of adoption, with Black and Asian children spending more time in care before adoption recommendations are made (Selwyn, Quinton, Harris, Wijedasa, Nawaz and Wood, 2010). It has been argued that an over-emphasis on ethnicity or cultural matching continues to cause delay in placing children with their adoptive families (Farmer and Dance, 2015).

Children with disabilities are also more like to face delay in placement (Avery, 2000; Baker, 2007; Sturgess and Selwyn, 2007). Often, adoptive placements for disabled children are not found at all (Selwyn, Sturgess, Quinton and Baxter, 2006). Whilst there seems to be a willingness by many prospective adopters to consider parenting a child with a 'mild' disability, those with moderate or severe difficulties tend to be discounted (Burge, Burke, Meiklejohn and Groll, 2015).

Children's behaviour at the time of entry into care has been shown to be influential in determining whether or not adoptive placements are made. Connell, Katz, 
Saunders and Tebes (2006) found that children with a diagnosed emotional or behavioural disorder were significantly less likely to be adopted. Leathers, Spielfogel, Gleeson and Rolock, (2012) found that whilst externalizing behaviour problems were negatively associated with the likelihood of adoption, internalizing behaviours, such as depression and anxiety, were not. The harmful effects of exposure to domestic violence (or intimate partner violence) on children is well established (Carpenter and Stacks, 2009). We wondered whether the timeliness of an adoptive placement was influenced by children's known exposure to domestic violence. To our knowledge, no systematic research has been conducted in this area.

\section{Procedural factors influencing the timeliness of adoption}

The process of matching children to their adoptive parents has been highlighted as a factor affecting the timeliness of placements. Particular issues include a reluctance from agencies to widen their search for adopters at an early stage; the provision of incomplete information about children and/or adopters; downplaying the complex needs of some children; and drift in the matching process (Farmer and Dance, 2015; Dance, 2015). A range of behavioural and attitudinal biases from social workers has also been identified as contributing to delay (Behavioural Insights Team, 2015; Farmer and Dance, 2015; Selwyn, Sempik, Thurston and Wijedasa, 2009). The decision to place children together for adoption as part of a sibling group can affect the timeliness of placements (Sinclair, 2007; Saunders and Selwyn, 2011).

Within the legal arena, the use of voluntary accommodation (section 20 of the Children Act 1989), as a route into care, has been criticised as contributing to placement delay (Ofsted, 2012; Doughty, 2016). Children under the age of 16 can only be accommodated under section 20 when those with parental responsibility give consent. Lengthy care proceedings caused by repeat or late assessments on birth parents or kin 
have also been identified as a contributory factor in placement delay (Selwyn et al., 2010; Ofsted, 2012). The 26-week time limit on proceedings is premised on an expectation that these assessments will be completed prior to the court application being issued.

Collectively, this brief overview of the literature highlights a range of factors that can impact on the length of time taken for a child to be placed for adoption. However, the relative importance of these different factors in determining the time to adoption has, to date, received little attention. This article compares the magnitude of various factors associated with the length of time children spend in care before moving to an adoptive placement. The evidence derives from data collected as part of the Wales Adoption Study. As of 31 $1^{\text {st }}$ March 2015, 5617 children were in local authority care in Wales. Five percent $(n=274)$ of these children were in an adoptive placement, awaiting legalisation of the adoption (Statistics for Wales, 2015).

\section{Method}

\section{Wales Adoption Study}

The Wales Adoption Study is a national research study that used a mixed-methods approach to examine the characteristics and experiences of children recently placed for adoption in Wales, to consider the early support needs of adoptive families into which a sample of these children were placed, and to better understand what helps these families to flourish.

\section{Ethical considerations}

Ethical permission for the study was granted by the Research Ethics Committee at Cardiff University, School of Social Sciences. Initial permission was obtained from the Welsh Government to access the local authority data. We then approached and consulted with the Heads of Children's Services Group and then Senior Adoption managers across 
Wales to secure their approval to contact social work teams and access records. The multidisciplinary advisory group for the study provided valuable guidance for developing best practice with respect to the ethics pertaining to safeguarding and data protection. As the research team had no access to the details of those adoptive families eligible for participation in the study, Local Authority social work teams sent out letters on our behalf to prospective families. Families who wanted to take part in the study contacted the research team directly.

\section{Data collection}

Data was drawn from case file records, questionnaires to adoptive families and interviews with adoptive parents. This article focusses on the information derived from the case file records, specifically those records containing the Child Assessment Reports for Adoption.

Child Assessment Reports for Adoption (CARA) records: Three hundred and seventy four CARA records were reviewed. The sample comprised the records of all children placed for adoption by every local authority (LA) in Wales between 01 July 2014 and 31 July 2015. The CARAs contain the information that local authorities must include when reporting on children put forward for adoption, as set out in the Adoption Agencies (Wales) Regulations (2005). They report on children's experiences and needs within the domains of health, education, emotional/behavioural development, self-care skills, identity, family and social presentation. The CARAs also provide a record of the characteristics and experiences of the children's birth parents, the given reasons children were placed for adoption and the actions taken by the LA. CARAs are completed by social workers, who record information based on their work with the birth parents, contact with foster carers, liaison with other professionals (such as police, health visitors and medical officers) and reviews of historical social services records. Under the Adoption Agencies (Wales) Regulations 2005, adoptive parents 
should be provided with the CARA when matched with a child, so that they have detailed information about the child and their pre adoption experiences.

About two-thirds of the CARAs reviewed were in electronic format, whilst the remainder were reviewed from a hard copy of the report. The researchers worked on site at the LA offices, and to avoid errors in copying, entered data directly into an SPSS database. More than 250 discrete pieces of information were sought from each CARA record. Regular meetings were held between the researchers reviewing the case files to maintain a common understanding of, and consistent approach, to coding. The parameters of most variables were unambiguous. Those that had the potential to be coded more subjectively (for example, attachment difficulties) were thoroughly considered. It was agreed that team members would not make judgements about the existence of factors, based on an interpretation of what a social work report might suggest. Variables were recorded as present only when they were specifically documented in the CARA as being so. The strengths and limitations of using case file records for research purposes are addressed in the discussion.

As well as providing valuable information about the characteristics, needs and experiences of all children placed for adoption by every LA in Wales over a 13 month period, the information extracted from the CARAs was also used to check the extent to which the children in those adoptive families who participated in other strands of the study (the questionnaires and interview work), were representative of all children placed for adoption in Wales during the study period.

We present the data derived from 361 CARA records, to examine the relationship between time spent in care before being placed for adoption and key characteristics (variables) relating to the child and their experiences. Of the 374 CARAs reviewed, 13 cases were excluded from the analysis because key data needed for study 
variables was not recorded in the child's report. There was up to $3 \%$ missing across the study variables. No statistical differences were found between those cases with complete versus missing data for the study variables of interest.

\section{$\underline{\text { Measures }}$}

Table 1 describes the study variables used for the analysis in this paper. The dependent variable was derived by calculating the period in days from the date the child came into care (became looked after either under section 20 or under a court order) to the date they were placed for adoption. For the small number of children $(n=28,8 \%)$ with more than one care episode, the date of their last entry to care was used for calculation purposes.

The variables of interest for the analysis included child characteristics and experiences and procedural factors that have been identified from the existing literature to be linked with placement delay. We defined a procedural factor as one which comprised the act of proceeding in an action relating the adoption process. The information extracted from the CARA was, in most cases, coded for each variable as either absent (0) or present (1).

The inclusion of an absent/present variable for 'birth parent mental illness' was not straightforward. It was often not possible to discern from the CARAs whether or not birth parents had a clinical diagnoses for anxiety and/or depression. Very many birth mothers (and some fathers) were simply described in the CARA as depressed or anxious, others were not described in this way but were reported to be taking prescribed anti-anxiety or anti-depressant medication. The ambiguity around whether or not a personality disorder should be classed as a mental illness (Kendell, 2002), further complicated identification of the variable parameters. 
The decision to include the 'mental illness' variable arose from anecdotal evidence that adopters may be more reluctant to consider parenting children whose birth parents have certain diagnosed mental illnesses. Notably, anxiety and depressive conditions do not seem to attract the concern among prospective adopters that other illnesses (such as schizophrenia and bipolar disorder) do. In view of the context in which inclusion for this variable emerged and due to the difficulties in identifying which birth parents had been formally diagnosed with depression and/or anxiety, we excluded these two conditions from our mental illness variable. For the purposes of this study, diagnosed personality disorders were included in this variable.

\footnotetext{
***Insert Table 1 about here ${ }^{* * * *}$
}

A decision was made to exclude the region in Wales from which the child was placed as a variable. This is because the five regional collaboratives now functioning in Wales did not exist at the outset of the study; all were formed at various times during the study period. Before regionalisation, children in Wales were placed for adoption by one of 22 local authorities. Whilst some of the children in the sample were placed under the auspices of a regional collaborative, others were placed by an individual local authority that had not yet merged.

\section{Statistical analysis}

Data analysis was conducted using SPSS Version 20.0 (IBBM Corp, 2011). Analysis was completed in two stages. First, the relationship between the length of time spent in LA care before being placed for adoption and each variable of interest was explored using Pearson's point-biserial correlations. Second, a multiple regression was used to investigate the relationship between the time spent in LA care before being 
placed for adoption and those variables which showed a significant association based on the results of the Pearson correlation.

\section{Results}

\section{Sample characteristics (listwise $n=361$ )}

Just over half (55\%) of children in the study were male; the majority were white British (95\%). Most children had no recorded religious orientation; those that did were mainly identified as Christian. English was the first language for nearly all the children in the study. Most children (92\%) had been removed from their birth home just the once. The average age of children on entry into care (final entry if removed more than once) was one year and two months (range 0 months to $6 \frac{1}{2} 2$ years). Just over two fifths (41\%) of the children entered care at, or shortly after birth, whilst just $6 \%$ did so after the age of four. A third (33\%) of all children in the sample were placed for adoption as part of a sibling group. Further descriptive data can be seen in table 2 . The average (mean) number of days between entry into care and adoptive placement was 528 days; the median was 434 days (range 129 to 2662 days).

\section{***Insert Table 2 about here $* * *$}

Pearson's point-biserial correlations were used to examine associations with the 12 variables of interest (table 3 ). An association was found between the age of the child on entry into care and length of time to placement $(r=.26, p<.01)$. Positive associations were also identified between length of time to placement and serious and enduring health problem or disability ( $\mathrm{rpm}=.24, \mathrm{p}<.01)$, developmental delay ( $\mathrm{rpm}=.31, \mathrm{p}<.01)$, externalising behaviour (rpm $=.30, p<.01)$, attachment concerns $(r p m=.18, p<.01)$ and exposure to domestic violence $(r p m=.23, p<.01)$. Adoption as part of a sibling group 
was not associated with length of time to placement $(r p m=.10)$. Similarly, no association was identified between the length of time spent in care before being placed for adoption and any of the following characteristics: gender, ethnicity, known paternity, birth parent mental illness, placement as part of a sibling group, kinship assessments and the recorded use of section 20 as the route into care.

***Insert Table 3 about here ${ }^{* * *}$

Using the variables that were significantly associated with number of days to placement in the correlation analysis $(p<.05)$, a multiple regression model using the enter method was used to examine the relative role of these factors in relation to the length of time between becoming looked after and being placed for adoption. The variance inflation factor values (VIF, 1.03 to 1.75 ) and tolerance values (.57 to .97) suggested the absence of multicollinearity (Bowerman and O'Connell, 1990). Four variables (serious and enduring health problem or disability, developmental delay, externalising behaviour and domestic violence) added statistically significantly to the prediction of length of time taken to adoptive placement $(F(6,360)=19.699, p<.001$, adj. $R^{2}=.25$ ). Regression coefficients and $95 \%$ confidence intervals are presented in Table 4.

***Insert Table 4 about here ${ }^{* * *}$

\section{Discussion}

This comprehensive and timely study provides important evidence about the characteristics and experiences of a national sample of children recently placed for adoption in the UK. As the adoption reform programmes in both England and Wales 
continue to gather pace, the commitment to reducing delay in the adoption process remains central to the agendas. The purpose of the analysis described in this paper, was to further develop what is known about the timeliness of adoption, by systematically investigating the relative importance of factors that predict delay.

\section{Child characteristics}

Children who wait longer in care for an adoptive placement are a good proxy for those considered hard to place. Our study showed that developmental concerns, serious and enduring health problems, externalizing behaviour and exposure to domestic violence all predicted a lengthier care episode for children before being placed for adoption.

However, these findings do not concur with some of the current thinking about the characteristics of those children who wait longer in care for adoption. In the UK, children are considered hard to place for adoption if they are over the age of five, from a black and ethnic minority group, have a disability, or need to be placed as part of a sibling group (Adoption Leadership Board, 2015). There has been a focussed drive to find permanent families for children with these characteristics and, not unusually, they are placements with which Voluntary Adoption Agencies are tasked to source (Selwyn, Sempik, Thurston and Wijedasa, 2009).

We found that the association between the age of the child on entry into care and a longer time to placement was reduced to insignificance when examined in the context of other child characteristics. Notably too, a sibling group placement was not associated with a lengthier care episode. These findings may be explained by the recent proactive work by adoption agencies in recruiting prospective adopters willing to consider parenting older children and sibling groups. It may also be the case that the discourse around sibling groups being hard to place for adoption is not entirely 
accurate. There is some research evidence to suggest that sibling groups per se, may not be harder to place, but large sibling groups of three children or more (Quinton 2012; Saunders and Selwyn, 2011). We found that the 12 children in our study who were placed as part of a large sibling group (three or more) waited, on average, longer (804 days) for an adoptive placement than the sample average (528 days). However, the range was large (420 days to 1,554 days) and there were too few large sibling group placements in the sample to conduct any robust analysis.

We also found no association between ethnicity (white British vs. all other ethnicities) and length of time to adoptive placement. However, this finding must be treated with caution. Our study sample was a broadly ethnically homogenous group (95\% white British), so possibly underpowered to detect statistically significant associations. Notably, however, the ethnic profile in our study was not dissimilar to that of the population in Wales, where the 2011 census showed that $93.2 \%$ of the Welsh population identified as white British.

\section{Matching and delay}

A recent paper by Farmer and Dance (2015) examined family finding in adoption. It reported on the causes of delay during the matching stage, including agencies' reluctance to widen their search in a timely manner for prospective adopters of hard to place children. In their study, some LAs had tried to avoid using VAAs to place children because of the perceived higher cost. However, the authoritative study by Selwyn and colleagues (2009) showed that when all costs are factored, VAA placements represent good value for money. To enhance the timeliness of adoption, family finders may want to consider, at an early stage, the complete range of resources available to them to help find suitable adopters for those children likely to wait longer than most for an adoptive placement. Our study provides contemporary evidence about the 
characteristics and experiences of such children.

From the questionnaire data generated from our study, we know that nearly a third (31\%) of adopters had been linked and/or matched to at least one other child, before being matched to the child now placed with them for adoption. We wondered how often those children with a lengthier care episode in the CARA sample had been linked to prospective adopters who, concerned about the challenges and uncertainties associated with the reported difficulties, had decided that the child would not be best cared for in their family. A record of the family finding activity was not available from the CARA data, so such analysis was not possible. This is a direction for future research.

\section{Procedural factors}

As well as providing good evidence about those child-related factors that predict a longer episode in care from our sample of recently placed children, the findings from our study can feed into the current debate about some of the procedural factors thought to be affecting the timeliness of adoption. The use of section 20 preceding the care application has been subject to severe judicial criticism in recent court judgments as responsible for causing drift and delay in achieving stable placements for children. This series of cases was described as 'a melancholy litany' by the President of the Family Division, Sir James Munby, in a Court of Appeal judgment. He was so concerned about the 'misuse' of section 20 that he issued general guidance to all social workers on limiting the use of voluntary care arrangements (Doughty, 2016). There is no court oversight of section 20 arrangements, but these are part of the chronology presented to the court if and when a care application is made. Findings from our study show, however, that when section 20 was recorded as having been used as a route into care, there was no association with a lengthier care episode for children before being placed for adoption. 
Under the pre-proceedings protocol of the Public Law Outline in care proceedings, and in accordance with human rights principles, where adoption should be considered as 'a last resort', all potential options for kinship care must be explored, as a safe placement may be found for children in the extended family under a different type of court order. Concerns have been expressed that successive social work assessments of a range of potential carers might delay planning (Ofsted, 2012). In our study, there was clear evidence of social workers observing these principles, in considering kinship care. Findings showed that even when multiple kinship carers were identified and considered, there was no statistically significant delay in the eventual placement of children with their adoptive family. We cannot comment, however, on how thoroughly prospective kinship carers were assessed.

There is evidence to suggest that the involvement of a child's father in care proceedings can delay the process, partly because fathers tend to become parties in court proceedings later than mothers, which then adds to the length of the case (Masson, 2008). We had wondered whether the timeliness of adoption might be associated with children whose birth father was unknown or undisclosed to the LA. In the event, unknown paternity was not associated with either expedited or delayed time to adoption.

\section{Strengths and limitations}

This is the first comprehensive study of the numbers and characteristics of adopted children in the UK since the report on 116 English LAs in 1999 (Ivaldi, 2000). We have analysed information from the Child Adoption Reports for a complete cohort of children placed for adoption in Wales over a 13 month period, from $1^{\text {st }}$ July 2014 to $31^{\text {st }}$ July 2015 . The size of the sample has provided an opportunity to explore the factors 
predicting timeliness of adoption within the current UK context with some measure of confidence.

The use of information contained within Child Adoption Reports is not, however, without its difficulties. As Quinton (2012) and Farmer and Dance (2015) observe, information is sometimes missing or inaccurate within case file records, and relies on social workers to interpret and make sense of very complex information which may not be within their field of expertise (for example medical and psychological information). This is potentially problematic because recommendations regarding current and future support needs are made on the basis of the information contained within the CARA.

Within the present study, we found that data was occasionally missing and/or possibly inaccurate, particularly in relation to concerns about attachment and development. For example, developmental delay was occasionally recorded in the CARAs, based on social workers interpretation of a child's presentation, but in the absence of any objective measure or corroborating medical evidence. The information recorded by social workers about children's attachment behaviour was not always consistent with their conclusions about the children's related attachment needs and difficulties. In their case note review, Woolgar and Baldock (2015) examined the reporting of attachment problems in fostered and adopted children. They compared community referrals (from social care practitioners, General Practitioners and paediatricians) with specialist assessments of attachment disorder. Their findings showed that attachment disorders and attachment problems were cited far more frequently in the referral letters than were diagnosed from the expert assessments. One of the recommendations from the National Assembly for Wales, Inquiry into Adoption (2012), was for social workers to address gaps in knowledge about child development, attachment theory and evidence-based practice. Our study findings suggest the need to better support social workers in these areas both pre- and post-qualification. We found 
that the evidence for some reporting in the CARA was not always explicit, nor was it clear whether information was being recorded in a systematic and consistent way nationally. We are concerned that the varied use of labels and terms may stigmatize children, raise anxiety amongst potential adopters and delay the making of suitable placements for a small number of children. We wonder whether (with appropriate training) using short and well-validated checklists as part of a holistic and systematic approach to social work assessment might assist social workers in accurately presenting the characteristics and needs of children awaiting adoption. Notwithstanding these minor limitations, given the size of the dataset, we are confident that robust conclusions can be drawn regarding the factors most likely to predict delay in placing children with their adoptive families.

\section{Conclusion}

This analysis investigated the length of time taken for children with a plan for adoption to be placed with their adoptive families. The findings from this study make a significant contribution to better understanding the factors that predict a lengthier care episode for a national sample of children recently placed for adoption in the UK. Such information, in turn, can help to inform adoption policy and practice, so that the plan for permanence can be realised for more children, within a timescale that meets their needs. The study shows that once in care, the greatest barriers to a timely adoption are when children present with developmental concerns, serious and enduring health problems or disability, externalizing behaviour and/or a history of exposure to domestic violence. We would urge adoption agencies to develop proactive strategies for finding families for children with these characteristics and experiences more swiftly. For example, consideration might be given to widening the search for

prospective adopters at the earliest opportunity. In further developing our 
understanding of those children considered hard to place, future work may usefully consider the characteristics of those children with a plan for adoption that never materialised.

\section{Acknowledgments}

Our sincere thanks go to the staff from the local authority adoption teams in Wales, who kindly assisted with supplying case file records and our research advisory group for their guidance. The study was funded by Health and Care Research Wales, a Welsh Government body that develops, in consultation with partners, strategy and policy for research in the NHS and social care in Wales (Grant reference: SC-12-04). The first author was supported by an Economic and Social Research Council doctoral studentship. 


\section{References}

Adoption Leadership Board (2015). Adoption Leadership Board Headline Measures and Business Intelligence: Quarter 4 2014-15 update. London: Department for Education.

Avery, R. J. (2000). Perceptions and practice: Agency efforts for the hardest-to-place children. Children and Youth Services Review, 22(6), 399-420.

Baker, C. (2007). Disabled children's experience of permanency in the looked after system. British Journal of Social Work, 37(7), 1173-1188.

Barth, R.P. and Berry, M. (1988). Adoption and disruption Rates, risks, and responses. Hawthorne, NY: Aldine de Gruyter.

Behavioural Insights Team (2015). Exploring adoption 'matching' decisions London: Behavioural Insights Ltd.

Biehal, N., Ellison, S., Baker, C. and Sinclair, I. (2010). Belonging and Permanence: Outcomes in long-term foster care and adoption. London: British Association for Adoption and Fostering (BAAF).

Boddy, J. (2013). Understanding Permanence for Looked-After Children: A Review of Research for the Care Inquiry. London: Care Inquiry.

Bowerman, B.L. and O'Connell, R.T. (1990). Linear statistical models: an applied approach (2nd edition). Belmont, CA: Duxbury.

Brown, R. and Ward, H. (2013). Decision making within a child's timeframe. London: Child Wellbeing Research Centre.

Burge, P., Burke, N., Meiklejohn, E. and Groll, D. (2015). Making Choices: Adoption Seekers' Preferences and Available Children with Special Needs. Journal of Public Child Welfare, 1-22.

Carpenter, G. and Stacks, A. (2009). Developmental effects of exposure to intimate partner violence in early childhood: a review of the literature. Children and Youth Services Review, 31, 831-839.

Connell, C. M., Katz, K. H., Saunders, L. and Tebes, J. K. (2006). Leaving foster care - The influence of child and case characteristics on foster care exit rates. Children and Youth Services Review, 28(7), 780-798.

Dance, C. and Rushton, A. (2005). 'Joining a new family: The views an experiences of young people placed with permanent families during middle childhood'. Adoption \& Fostering, 29 (1), 18-28.

Dance, C. (2015). Finding the right match: a survey of approved adopters' experiences of agency support in the linking and matching process. Adoption Link and University of Bedfordshire. 
Department for Education (2012). Adoption Action Plan for Tackling Delay: Associated resources, working Groups report on redesigning adoption. London: The Stationery Office.

Department for Education (2015) The Children Act 1989 Guidance and Regulations and Guidance Volume 2: Care planning, placement, and case review. DFE 00169-2015.

Doughty, J. (2016) 'More judicial guidance for local authorities in care proceedings: $R e$ N (Children; Adoption; Jurisdiction) [2015] EWCA Civ 1112' Journal of Social Welfare and Family Law, DOI: 10.1080/09649069.2016.1156885.

Family Justice Review (2011) Final report. Ministry of Justice, Department for Education \& Welsh Government.

Farmer, E. and Dance, C. (2015). Family Finding and Matching in Adoption: What Helps to Make a Good Match? British Journal of Social Work, DOI: 10.1093/bjsw/bcv003.

Gupta, A. and Lloyd-Jones, E. (2014). Re B-S: a glass half full? An exploration of the implications of the Re B-S judgment on practice in the family courts. Child \& Family Social Work.

Harden, B. J. (2004). Safety and stability for foster children: A developmental perspective. The Future of Children, 31-47.

IBM Corp. (2011). IBM SPSS Statistics for Windows, Version 20.0. Armonk, NY: IBM Corp.

Ivaldi, G. (2000). Surveying adoption: a comprehensive analysis of local authority adoptions 1998-1999 in England London: BAAF.

Kendell, R. (2002). The distinction between personality disorder and mental illness. The British Journal of Psychiatry, 180 (2) 110-115.

Leathers, S. J., Spielfogel, J. E., Gleeson, J. P. and Rolock, N. (2012). Behavior problems, foster home integration, and evidence-based behavioral interventions: What predicts adoption of foster children? Children and Youth Services Review, 34(5), 891-899.

Lloyd, E. C. and Barth, R. P. (2011). Developmental outcomes after five years for foster children returned home, remaining in care, or adopted. Children and Youth Services Review, 33(8), 1383-1391.

Masson, J. (2008). 'Controlling costs and maintaining services - the reform of legal aid fees for care proceedings' Child and Family Law Quarterly 20 pp 425-448.

National Adoption Service (2015). Annual Report 2014-2015 Cardiff: National Adoption Service.

National Assembly for Wales (2012). Children and Young People Committee Inquiry into Adoption. Cardiff.

Ofsted (2012). Exploring delays in adoption: right on time. Office for Standards in Education, Children's Services and Skills. 
Palacios, J. and Brodzinsky, D. (2010). 'Review: Adoption Research: Trends, topics, Outcomes' International Journal of Behavioral Development 34 (3), 270 - 284.

Quinton, D. (2012). Rethinking matching in adoptions from care: a conceptual and research review. BAAF.

Rubin, D.M., O'Reilly, A.L., Luan, X. and Localio, A.R. (2007). The impact of placement stability on behavioral well-being for children in foster care. Pediatrics, 119(2), 336344 .

Saunders, H. and Selwyn, J. (2011). Adopting large sibling groups: The experiences of adopters and adoption agencies. London: BAAF.

Selwyn, J., Sturgess, W., Quinton, D., and Baxter, C. (2006). Costs and Outcomes of NonInfant Adoptions. London: BAAF.

Selwyn, J., Quinton, D., Harris, P., Wijedasa, D., Nawaz, S. and Wood, M. (2010). Pathways to Permanence for Black, Asian and Mixed Ethnicity Children, London: BAAF.

Selwyn, J., Sempik, J.,Thurston, P. and Wijedasa, D. (2009). Adoption and the InterAgency Fee. London: Department for Children Schools and Families.

Selwyn, J., Meakings, S. and Wijedasa, D. (2015). Beyond the adoption order: challenges, interventions and adoption disruption. London: BAAF.

Sinclair, I. (2007). The pursuit of permanence: A study of the English care system. Jessica Kingsley Publishers.

Statistics for Wales (2015). SDR 152/2015: Adoptions, Outcomes and Placements for Children Looked After by Local Authorities, Wales, 2014-15. Welsh Government.

Sturgess, W. and Selwyn, J. (2007). Supporting the placements of children adopted out of care. Clinical Child Psychiatry and Psychology, 12: 13-29.

van den Dries, L., Juffer, F., van IJzendoorn, M. H. and Bakermans-Kranenburg, M. J. (2009). Fostering security? A meta-analysis of attachment in adopted children. Children and youth services review, 31(3), 410-421.

van Ijzendoorn, M.H. and Juffer, F. (2006). 'The Emanuel Miller lecture 2006. Adoption as intervention. Meta-analytic evidence for massive catch-up and plasticity in physical, socio-emotional, and cognitive development'. Journal of Child Psychology and Psychiatry, 47: 1228-1245.

Wijedasa, D. and Selwyn, J. (2014). Beyond the adoption order: an investigation of adoption disruption in Wales. Welsh Assembly Government.

Woolgar, M. and Baldock, E. (2015). Attachment disorders versus more common problems in looked after and adopted children: comparing community and expert assessments. Child and Adolescent Mental Health, 20(1), 34-40. 
Zima, B. T., Bussing, R., Freeman, S., Yang, X., Belin, T. R. and Forness, S. R. (2000). Behavior problems, academic skill delays and school failure among school-aged children in foster care: Their relationship to placement characteristics. Journal of Child and Family Studies, 9(1), 87-103. 
Table 1: Study variables.

\begin{tabular}{|c|c|}
\hline$\underline{\text { Variable }}$ & Definition \\
\hline Age of child & Age of child on (final) entry into care. \\
\hline Sex & Gender of child. \\
\hline Ethnicity & $\begin{array}{l}\text { Ethnicity of child (white British vs. all other ethnic } \\
\text { groups). }\end{array}$ \\
\hline $\begin{array}{l}\text { Serious \& enduring health } \\
\text { problem/disability }\end{array}$ & $\begin{array}{l}\text { Serious and enduring health problem or disability, } \\
\text { including for example, cerebral palsy, muscular } \\
\text { dystrophy, chromosomal abnormalities (e.g. Downs } \\
\text { Syndrome), major sensory impairment. Excludes } \\
\text { emotional and behavioural disorders. }\end{array}$ \\
\hline Developmental delay & $\begin{array}{l}\text { Not achieved developmental milestones within the } \\
\text { normal age range in one or more domains (physical, } \\
\text { language, cognitive, social and emotional). }\end{array}$ \\
\hline Externalizing behaviour & $\begin{array}{l}\text { Age inappropriate behaviour problems manifested in } \\
\text { children's outward presentation, comprising sustained } \\
\text { disruptive, hyperactive, and aggressive behaviours. }\end{array}$ \\
\hline Attachment concerns & $\begin{array}{l}\text { Concerns identified by child social worker regarding the } \\
\text { child's attachment behaviour. }\end{array}$ \\
\hline Domestic violence & $\begin{array}{l}\text { Coded as present only when domestic violence was } \\
\text { confirmed through birth parent report or formal } \\
\text { documentation (e.g. police or medical reports). }\end{array}$ \\
\hline Birth father known & Identity of birth father known to Local Authority. \\
\hline Birth parent mental illness & $\begin{array}{l}\text { Either birth parent had diagnosed mental illness or } \\
\text { personality disorder (excludes anxiety/depression). }\end{array}$ \\
\hline Sibling group placement & Child placed for adoption together with siblings. \\
\hline $\begin{array}{l}\text { Multiple kinship care } \\
\text { assessment }\end{array}$ & $\begin{array}{l}\text { Multiple named members of wider birth family / } \\
\text { friendship network considered as possible carers for } \\
\text { child before being placed for adoption. }\end{array}$ \\
\hline Use of Section 20 & $\begin{array}{l}\text { Child recorded as having been accommodated under } \\
\text { Section } 20 \text { Children Act 1989, before care proceedings } \\
\text { began. }\end{array}$ \\
\hline
\end{tabular}


Table 2: Descriptive information for the dichotomous study variables as recorded in the Child Assessment Reports for Adoption ( $\mathrm{n}=374$ ).

\begin{tabular}{llll}
\hline Variable & Number & $\underline{0}$ & $\underline{\text { Available N }}$ \\
\cline { 2 - 4 } Sex (male) & 205 & 54.8 & 374 \\
Ethnicity (white) & 353 & 94.6 & 37 \\
Serious \& enduring health problem/disability & 22 & 5.9 & 372 \\
Developmental delay & 67 & 18 & 372 \\
Externalizing behaviour & 60 & 16.1 & 373 \\
Attachment concerns & 61 & 16.4 & 373 \\
Domestic violence & 135 & 36.5 & 370 \\
Birth father known & 331 & 88.5 & 374 \\
Birth parent mental illness & 51 & 13.6 & 374 \\
Sibling group placement & 122 & 32.6 & 374 \\
Multiple kinship care assessment & 97 & 26.6 & 365 \\
Use of Section 20 & 160 & 43 & 372 \\
\hline
\end{tabular}


Table 3 Inter-correlations among the study variables

\begin{tabular}{|c|c|c|c|c|c|c|c|c|c|c|c|c|c|c|}
\hline & & 1 & 2 & 3 & 4 & 5 & 6 & 7 & 8 & 9 & 10 & 11 & 12 & 13 \\
\hline & $\underline{\text { Child characteristics }}$ & & & & & & & & & & & & & \\
\hline 1. & Age of child when placed in care & -- & & & & & & & & & & & & \\
\hline 2. & Gender $(0=$ male $)$ & -.04 & -- & & & & & & & & & & & \\
\hline 3. & Ethnicity ( $0=$ white British) & $-.13^{*}$ & $.12^{*}$ & -- & & & & & & & & & & \\
\hline 4. & Serious health problem or disability & .03 & -.03 & .04 & -- & & & & & & & & & \\
\hline 5. & Concerns about development & $.16^{* *}$ & $-.14^{*}$ & -.02 & $.14^{*}$ & -- & & & & & & & & \\
\hline 6. & Behaviour problems & $.51^{* *}$ & $-.12^{*}$ & $-.11^{*}$ & .02 & $.14^{* *}$ & -- & & & & & & & \\
\hline 7. & Concerns about attachment & $.36^{* *}$ & -.04 & -.07 & .02 & .07 & $.30^{* *}$ & -- & & & & & & \\
\hline 8. & Domestic violence & $.48^{* *}$ & -.07 & $-.11^{*}$ & -.09 & .03 & $.28^{* *}$ & $.20 * *$ & -- & & & & & \\
\hline 9. & Father known & $.12^{*}$ & -.05 & -.10 & -.02 & .01 & .07 & .05 & $.22 * *$ & -- & & & & \\
\hline 10. & Child adopted as part of sibling group & $.38^{* *}$ & .08 & $-.12^{*}$ & -.05 & .04 & $.19 * *$ & .06 & $.35^{* *}$ & $.15^{* *}$ & -- & & & \\
\hline 11. & Multiple kinship care assessment & .03 & .09 & $.13^{*}$ & -.02 & .00 & .04 & .00 & .09 & .08 & .09 & -- & & \\
\hline 12. & Section 20 & -.02 & -.10 & .01 & $.12^{*}$ & .01 & .09 & .07 & -.03 & -.06 & -.03 & -.03 & -- & \\
\hline 13. & Birth parent mental illness & $-.11^{*}$ & -.09 & -.03 & .04 & -.08 & -.07 & -.07 & -.02 & .05 & -.06 & .01 & .06 & \\
\hline 14. & $\begin{array}{l}\text { Number of days between child being } \\
\text { placed in Local Authority care and } \\
\text { commencement of placement for } \\
\text { adoption. }\end{array}$ & $.26^{* *}$ & -.06 & .02 & $.24^{* *}$ & $.31^{* *}$ & $.30^{* *}$ & $.18^{* *}$ & $.23^{* *}$ & -.01 & .10 & .05 & -.04 & -.01 \\
\hline
\end{tabular}

Listwise $\mathrm{N}=361 ;{ }^{*} p<.05,{ }^{* *} p<.01$. 
Table 4: Results of regression analysis predicting length of time between becoming looked after and being placed for adoption.

\begin{tabular}{llll}
\hline & B (95\% CI $)$ & SE B & $\underline{\beta}$ \\
\hline Constant & $391.14(350.26,432.02)$ & 20.79 & \\
Age of child at entry to care & $0.01(-.06, .08)$ & .04 & .02 \\
Serious \& enduring health problem/disability & $301.55(174.96,428.15)$ & 64.38 & $.22^{* * *}$ \\
Concerns about developmental delay & $211.16(132.93,289.38)$ & 39.78 & $.25^{* * *}$ \\
Externalising behaviour & $161.88(68.83,254.93)$ & 47.32 & $.19^{* *}$ \\
Attachment concerns & $53.26(-31.70,138.21)$ & 43.20 & .06 \\
Domestic violence & $114.92(45.63,184.21)$ & 35.24 & $.17^{* *}$
\end{tabular}

Note: $\mathrm{R}^{2}=.23^{*} p<.05^{* *} p<.01,{ }^{* * *} p<.001 ; \mathrm{B}=$ unstandardized regression coefficient; $\beta=$ Standardized coefficient. 